International Journal of Child, Youth and Family Studies (2014) 5(3): 447-465

\title{
CHANGE, RELATIONSHIPS AND IMPLICATIONS FOR PRACTICE: THE EXPERIENCES OF YOUNG PEOPLE WHO USE MULTIPLE SERVICES
}

\section{Katie Stevens, Robyn Munford, Jackie Sanders, Linda Liebenberg, and Michael Ungar}

\begin{abstract}
Despite the range of life changes experienced by young people who are multiple service users (MSU), many demonstrate remarkable levels of optimism. This article reports on the changes in living arrangements (including out-of-home placements), schooling, and social workers, experienced by a sub-sample of 16 multiple service using young people with complex needs who participated in a mixed methods study ( $n=605$ ). Case file data and qualitative interviews were analysed in order to understand young people's experiences of change and the factors that supported them to adapt positively to these. The findings revealed that change disrupted service delivery but that the active involvement of family and at least one service provided more effective support for young people experiencing change than either of those resources alone. Memories and imaginations of family may act as an emotional co-presence or identity resource when active family support is unavailable. The findings provide an argument for relationship-based, long term service involvement with young people with complex needs which complements or supplements family relationships particularly when these are inactive.
\end{abstract}

Keywords: young people, change, resilience, service delivery, child welfare

Acknowledgements: The authors thank The Ministry of Business, Innovation and Employment for funding this research programme. They also gratefully thank all the young people and their supporters who participated in the research. They acknowledge the contribution of The Donald Beasley Institute, The Victoria University Research Trust and its staff, Youthline Auckland, Kapiti Youth Support, and all the other researchers who helped with the research. Finally they thank Child, Youth and Family for providing access to case files and for providing very valuable feedback and peer review of this paper.

Katie Stevens, MSW, (the corresponding author) is a Principal Analyst at the Families Commission, working with the Practice Research Hub at Massey University, Palmerston North 4474, New Zealand. E-mail: K.A.Stevens@massey.ac.nz

Robyn Munford, Ph.D. is Professor in the School of Health and Social Services, Massey University, Palmerston North 4474, New Zealand. E-mail: R.Munford@massey.ac.nz

Jackie Sanders, Ph.D. is Associate Professor in the School of Health and Social Services, Massey University, Palmerston North 4474, New Zealand. E-mail: J.Sanders@massey.ac.nz

Linda Liebenberg, Ph.D. is Co-Director of the Resilience Research Centre at Dalhousie University, 6420 Coburg Rd., P.O. Box 15000, Halifax, Nova Scotia B3H 4R2, Canada.

E-mail: Linda.Liebenberg@dal.ca

Michael Ungar, Ph.D. is Professor of Social Work at Dalhousie University, 6420 Coburg Rd., P.O. Box 15000, Halifax, Nova Scotia B3H 4R2, Canada. E-mail: michael.ungar@dal.ca 
Young people with complex needs who become involved in multiple services have commonly had at least one experience that has shaken their lives. While enhancing stability is a key goal of most interventions, young people with complex needs often experience changes in living arrangements, educational services, and workers during their journey through services. Despite these changes, some young people demonstrate remarkable levels of optimism and an ability to survive (Ungar, 2001). This article explores the factors which helped young people to positively manage change, including the resources and relationships they drew on, and considers implications for social work practice. Findings are based on analysis of data collected for the qualitative component of a mixed methods study of young people who use multiple services in New Zealand (Sanders et al., 2013c).

\section{The Effects of Change on Young People's Outcomes}

While for most young people changes in circumstance, such as moving home or school, can be disruptive, they are nonetheless commonplace. Times of change, for example a move to boarding school, may even provide improved opportunities (Plumridge \& James, 2011). For young people with complex needs, however, there is evidence that change and mobility are correlated with poorer outcomes (Plumridge \& James, 2011; Stein, 2006).

\section{Effects of placement changes}

The experience of multiple placements is well researched within the looked-after children literature, with evidence of correlations between multiple placement moves and negative outcomes for young people. These include behavioural problems, offending, poor educational achievement, unemployment, and mental health problems (Cashmore \& Paxman, 2006; Rock, Michelson, Thomson, \& Day, 2013; Stein \& Munro, 2008). Short-term placement instability (occurring soon after a young person enters care) may not be harmful if there is a positive reason for change that the young person understands and accepts. However, prolonged instability has negative effects (Barber \& Delfrabbo, 2006). Research suggests placement instability affects young people's outcomes in part by undermining existing support networks and minimising opportunities to develop new relationships; repeated changes may cause young people to become disillusioned (Holland \& Crowley, 2013; Rock et al., 2013) but also self-reliant (Jakobsen, 2012). As Driscoll (2011) states:

Having been let down, as they saw it, both by their birth families and professionals, self-reliance was regarded as a positive attribute, recounted with some pride and emphasised particularly by the boys. (p. 25)

Self-reliance as a consequence of placement changes is not entirely positive. Schofield and Beek (2009) note young people who become prematurely self-reliant are unlikely to thrive with only personal resources to draw on.

Placement instability has been a concern in New Zealand and internationally (Atwool, 2010; Rock et al., 2013; Tarren-Sweeney, 2008). While placement stability is important, young people's perceived security has been identified as a more significant predictor of outcomes (Cashmore \& Paxman, 2006). Cashmore and Paxman (2006) suggest placement stability contributes to "felt" security by building young people's access to relationships, sense of belonging, and long-term support networks (Cashmore \& Paxman, 2006; Schofield 
\& Beek, 2009; Stein \& Munro, 2008). They identify placement stability and continuity as "the best default options" for “felt” security (Cashmore \& Paxman, 2006, p. 239).

\section{Effects of changes in education}

Changing schools can result in disruptions to a young person's education with negative consequences for their academic outcomes and future opportunities (Driscoll, 2011; Plumridge \& James, 2011). This, combined with other factors such as low expectations from teachers and problematic relationships with carers (Driscoll, 2011), contributes to poor outcomes for children in care. School changes disrupt relationships with peers (Fernandez, 2006) and with key adults in the school setting who provide support to students. The literature suggests that where there is education and placement stability, care leavers are more likely to remain at school and move into higher education (Driscoll, 2011; Stein, 2006).

\section{Effects of changes in social workers and services}

Young people with complex needs often experience changes in social workers and caregivers during their involvement with services. These changes, including discharge from a service, are likely to be experienced as a loss and where clients perceive that their needs have not been met, such endings can "reactivate feelings of being abandoned" and increase vulnerability (Solomon, 2010, p. 178). Multiple worker changes are strongly correlated with placement instability (Rock et al., 2013) which in turn is correlated with poorer outcomes for young people (Stein, 2006).

\section{Change and relationships}

Attachment and identity theories (Ainsworth \& Bell, 1970; Chen, Lau, Tapanya, \& Cameron, 2012; Erikson, 1965; Schofield \& Beek, 2009) provide insight into how change impacts on young people's development and on their relationships. Attachment theory proposes infants need to develop a relationship with at least one caregiver in order for normal psycho-social development to occur, and that children use their "attachment figure" as a "secure base" which they return to after exploring their environment (Ainsworth \& Bell, 1970; Schofield \& Beek, 2009). Based on early attachments, people develop an internal working model - essentially a guide, based on experience - of how to understand the world, what to expect from relationships, and how to take part in these. Poor early relationships with or changes in caregivers can upset the capacity of infants and children to experience good quality attachments and relationships in the future and deprive young people of a secure base to draw on during times of change. Later relationships with caring and supportive adults or peers can have a compensatory effect (Stein, 2006), in particular by offering belonging, family membership, and a secure base (Schofield \& Beek, 2009).

Movement and change can also impact on a young person's sense of belonging and identity which is formed within the context of relationships with families, carers, friends, and communities (Chen et al., 2012; Schofield \& Beek, 2009; Smith, Kumar, Nicholson, \& Kumar, 2006; Snow, H, S, J, A \& P, 2013). When these relationships are constantly shifting young people may find it difficult to know where they belong which militates against them being able to form a consistent identity:

Constant changes can hardly fail to reinforce the impression that nothing can be expected to endure, including a sense of self-persistence. (Ward, 2011, p. 2516) 
Without a strong sense of self to anchor them, young people in care may experience low selfesteem or be profoundly distressed by change. (Schofield \& Beek, 2009)

\section{Resources that Mediate Outcomes and Change}

Studies suggest young people's resilience resources help mediate their outcomes and moderate the effects of risk they face within their lives (Ungar, 2005). Such resources include factors in young people's individual make-up (for example, individual skills), relationships (for example, with family), and wider social environments (for example, cultural and community connections; engagement with education) and the way these interact. Given that change is correlated with negative outcomes for young people in care (Stein \& Munro, 2008), it could be argued that change acts as a risk for young people with complex needs and the resilience resources described above may moderate its effects.

For young people with complex needs, relationships with adults are a particularly important resource (Ungar, 2004), especially those that offer continuity, contribute to perceived security (Cashmore \& Paxman, 2006), and provide young people with a secure base (Schofield \& Beek, 2009) through periods of change. The relationships young people have with service providers (including caregivers) and their families are of particular interest in building an understanding of the factors that promote positive outcomes in youth. There is evidence that services that work effectively with young people, harnessing their existing resources to provide them with support, are more likely to have a positive influence on young people's outcomes (Sanders et al., 2013b) and that positive relationships with "reliable" workers can contribute to young people’s sense of security (Schofield \& Beek, 2009, p. 257).

The role of family relationships on young people's outcomes and experiences of change is complex. Regardless of damaged relationships or limited contact, there is some evidence to suggest that family continues to play a role in the lives of young people with complex needs. Previous studies (Biehal \& Wade, 1996; Holland \& Crowley, 2013) suggest young people in care, a group of youth with particularly complex needs, often hold an idealised view of family. As Holland and Crowley note:

The young people in our study often powerfully envisioned families they lived by, sometimes in the form of their birth families and the imagined alternative lives they might have lived with them, a longed for, stable substitute home or an imagined future family of their own. (p. 59)

These young people described an "emotional co-presence” (Holland \& Crowley, 2013, p. 61) of family in the form of memories and imaginations. There was also evidence that young people's interwoven biographies with their family played a particular role that was difficult to replicate in other relationships (Holland \& Crowley, 2013, p. 64).

The role of young people's relationships with their siblings is also important and should not be overlooked when attempting to understand the way in which relational supports can contribute to better outcomes for youth with complex needs. Evidence shows sibling coplacement reduces young people's negative behaviour, while separation is correlated with placement instability, although sibling conflict may also contribute to placement breakdown (Rock et al., 2013). Perhaps more importantly, Holland and Crowley (2013) found sibling relationships represented the most positive birth family relationships for children in care and described profound emotional consequences for some young people where these relationships 
were lost as a result of placements, particularly when one sibling had played a caregiving role.

Given that change and negative outcomes are correlated, that resources and positive outcomes are correlated, and that relationships are a particularly important resource for young people with complex needs, this article explores young people's experiences of change, the resources and relationships that had a positive bearing on their experiences of change, and considers some implications for social work practice.

\section{Methods}

This article is based on findings from the New Zealand Pathways to Resilience Research Programme (PtRP). The PtRP is a mixed methods study investigating the role that services (child welfare, juvenile justice, education, and mental health delivered by both statutory and non-government organisations) play in mitigating the effects of adversity and in maximising young people's resources and the potential for good outcomes in youth with complex needs. The PtRP is a cross-sectional study which will be advanced by the forthcoming Youth Transitions study which examines changing patterns in young people's risk, resilience, and service use over time. Ethical approval for the PtRP was granted by the Massey University Ethics Committee.

The quantitative phase of the PtRP consisted of a survey of 605 multiple service using youth (MSU), a survey with a matched comparison group of youth $(n=605)$, and a survey with a person nominated by the youth as knowing the most about them (PMK). Young people were aged between 12 and 17 and at the time of the research were clients of two or more service systems (juvenile justice, child welfare, alternative or special education services, or mental health services, both statutory and non-governmental). Youth were recruited from six geographical locations around New Zealand. Multiple service using youth faced high levels of risk located at the individual level (including delinquency, substance abuse, and depression), the family/whānau level (abuse, neglect, and poverty), and the community level (violence, social disorganisation, disengagement from education). The survey captured demographic information, young people's patterns of harm, their experiences of service use, their relationships with family and friends, and the role of material, social, and emotional resources in achieving functional outcomes including involvement in school, civic engagement, pro-social behaviour, positive peer group, and future aspirations (opportunities and optimism). It was administered by a trained interviewer.

The qualitative phase of the research involved interviews with young people ( $n=$ 109), case file reviews, and interviews with a PMK. Young people were identified for inclusion in the qualitative sub-sample based on their risk and resilience scores calculated from their responses to the survey. Those with the highest risk and the highest or lowest resilience scores were included in this sub-sample. The young people in the qualitative subsample gave permission for case file reviews to be completed for up to four of the services with which they had been involved (Sanders et al., 2013c).

Case file review data was collected using a template that included dates, description of the file item, and a summary of the file entry. Summaries captured the following information: why the service became involved, processes of assessment and investigation that informed decisions, interventions with the youth, and the rationale for case closure. File excerpts used in this article are summaries of file data made by researchers; they are not 
verbatim records from files for confidentiality reasons. Both the qualitative interviews and the file reviews were coded and analysed in NVivo, a qualitative data analysis software package.

The analysis used in this article is based on the case file reviews and interviews of 16 young people included in the qualitative sub-sample and comprises the eight young people with the highest resilience scores and the eight with the lowest resilience scores. This selection enabled comparisons to be made of differences in experiences of change and resilience resources for the group of MSU youth with the highest risk and with the highest and lowest resilience. Changes of living arrangements, schools, workers, and support services - and the young people's experiences of these according to their files and interviews - were analysed. Case files spanned between one day and 16 years. Thematic analysis was used to analyse the data. The findings reported in this article represent the major themes that emerged in this analysis. Pseudonyms have been used.

\section{Findings}

\section{Young people's experiences of change}

The young people in the sample experienced a broad range of change in their lives including: changes in living arrangements, housing, schooling, relationships and support networks. These changes were the consequences of events both within and beyond their control (for example, a parent going to prison, family violence, and/or the young person's own behaviours).

Table 1. Median number of changes by resilience group

\begin{tabular}{lll}
\hline & $\begin{array}{l}\text { Higher resilience group } \\
n=8\end{array}$ & $\begin{array}{l}\text { Lower resilience group } \\
n=8\end{array}$ \\
\hline $\begin{array}{l}\text { Median number of years } \\
\text { known to a single service }\end{array}$ & 8.6 & 4.1 \\
$\begin{array}{l}\text { Median number of changes in } \\
\text { living arrangements }\end{array}$ & 7 & 4.5 \\
$\begin{array}{l}\text { Median number of social } \\
\text { workers in a single service } \\
\begin{array}{l}\text { Median number of changes in } \\
\text { educational settings }\end{array}\end{array}$ & 4 & 4 \\
\hline
\end{tabular}

As shown in Table 1, young people who scored higher on resilience measures and had more resilience resources (higher resilience group) experienced a similar volume of change (of placements, schools, and workers) to those who scored lower and had fewer resilience resources (lower resilience group). However, the higher resilience group had longer histories of service involvement than the lower resilience group. 


\section{Changes in living arrangements}

While just under a third of the young people included in this analysis had never lived outside of their parents' care, the remainder, from both the higher and lower resilience groups, experienced between two and 37 moves. These were often a combination of moves instigated by families, placements instigated by services, and changes organised by young people themselves such as those that resulted from absconding from a previous living arrangement. Some young people experienced changes prior to their involvement with the services included in this analysis. These changes may have taken place when the young person was involved with a different service, when case files were closed or as the result of family court decisions.

More so than other types of change (for example, of school or social worker), changes in living arrangements had flow-on effects. Moves to new communities often resulted in changes of schools or educational settings, support services, interventions, and importantly, changes to young people's relationships and social networks as illustrated by the following file summary:

Anton moved continuously as a child due to mother's controlling behaviour. Mother was diagnosed with a mental illness. Due to constant moving Anton did not settle into school/peer relationships.

Young people exhibited a range of responses to the changes in their living arrangements. Caregivers reported challenges in managing young people's behaviours, young people themselves made complaints or requested moves, and some absconded. In both the files and the interviews there was evidence of youth sabotaging placements in an effort to return home, demonstrating control over their environments and identities (Ungar, 2001), or rejecting relationships with new carers before they had a chance to be rejected themselves (Solomon, 2010). Other young people responded well to particular placements and some reflected sadly on changes to placements where they had a good relationship with carers or with local peer groups. The following excerpt from a file summary illustrates the benefits youth gained from positive placements and also the desire youth had to return to those places that had contained good experiences:

Paoroa was clear that [residential placement] changed his life and outlook. Lots of activities - diving, fishing, hunting, doing things for community, counselling, group therapy. Felt like second home and secure. Company from the [elders]. Paoroa would go back if he could.

Data from both the file analyses and the qualitative interviews revealed that placement changes were often unplanned and frequently reacted to crises. Managing placement changes and responding to disruptions to these dominated much of recorded social work practice with young people. It was clear that considerable time and energy was expended on trying to secure consistent living arrangements for these youth. Changes in living arrangements appeared to have more far-reaching effects for young people than changes in schools and social workers which are discussed in the following sections. 


\section{Changes in schools}

Changes in schooling or educational services were a common experience. Of the 16 cases examined, only three young people had no recorded changes while three experienced at least seven changes in schools or educational services. Young people in the higher resilience group had more changes to their schooling, although this likely reflects that several of the young people in the lower resilience group no longer attended school and therefore did not experience school changes. Changes in schools were sometimes related to a young person's transient lifestyle with their family and had consequences for both academic progress and peer relationships. The following file summary illustrates this:

Anton participated well at school, was described as bright and academically able, but had not progressed in education due to his mother's transience.

Schooling changes were also commonly a result of placement moves as noted in the previous section. School expulsion and changes in educational services typically resulted from "acting out" behaviour; this trend was noted more frequently for young people in the lower resilience group. In many cases young people had experienced a trauma which contributed to the challenging behaviour they exhibited prior to being expelled. Files indicated that often a young person's use of alcohol or drugs precipitated a school expulsion. In these cases there was commonly a requirement by substance and mental health treatment services that youth attend all clinic appointments to retain their place in the service; youth were discharged from these services after three non-attendances regardless of whether their needs had been met. These practices had implications for education, welfare, and justice providers who were left managing the youth without clinical interventions.

Most of the young people expressed a desire to participate in education as a means to becoming independent and/or employed in the future; in a few cases young people's behaviours reflected this motivation. In one example, a young person spoke of his anxiety regarding the disruption his drug and alcohol rehabilitation was having on his ability to complete academic credits. Following the completion of his treatment he successfully reengaged with mainstream education.

Schools themselves had a role to play in whether or not young people experienced change. Youth and PMK did describe some schools and particular teachers as making great efforts to support youth to keep attending school. Others were less willing to "go the distance" particularly where young people displayed challenging behaviour, as described in the file excerpt below:

Mother did not want her son to go to [name of high school] because he was not wanted there and from experience she knew that when the school did not want a young person they would give up when things got hard.

Young people's responses to school moves were mixed. Files provided evidence of young people struggling to settle into new schools particularly where there was instability in other parts of their lives (for example, placement moves, court appearances, substance abuse) but also of young people responding well to school changes and making efforts to engage, particularly when other aspects of their lives (for example, placements) were stabilised. The following file excerpt demonstrates this: 
Jim seemed settled in residence and workers noted he participated well in activities such as creative writing with a staff member. He was described as enjoying the school programme and the structure of residence.

In addition to changes in living arrangements and schools, many young people experienced changes in workers, as described in the following section.

\section{Changes in workers}

As shown in Table 1, most of the young people had worked with multiple social workers; six young people had six or more workers within one service. The young person who had the most social workers (19) had been involved with one service for over 16 years; that service's involvement ranged from providing protective responses and placement options through to managing the young person's criminal offending. Young people commonly had multiple workers across agencies, or from different parts of the same agency (for example, a social worker, psychologist, counsellor, and residential social worker).

Reasons for changes in worker included allocation of more appropriate workers (those with greater experience, or better cultural or gender matches), previous workers leaving the service or changing roles, or as a result of files being transferred between offices when young people moved to a different geographical location. In a number of the files reviewed, the transfer of cases from one office to another (and consequent changes in workers) resulted in challenges, particularly regarding responsibility for funding (e.g., for school uniforms) and completion of case-related tasks. A number of files noted concerns from families or other professionals about the quality and timeliness of practice and the consequences (e.g., financial stress) for some families during periods when workers changed or cases were transferred. As noted, changes in living arrangements, schools, and social workers impacted on young people's relationships; these impacts are discussed in the following section.

\section{Impact of change on family relationships and service delivery}

For many young people, family relationships persisted where other relationships (for example, with caregivers, peers, school support networks, and social workers) fell by the wayside as the result of change. In the 16 files explored, most young people had some form of ongoing contact with their parents, although there were differences in the regularity and quality of this contact. It was particularly notable that the young people with higher resilience scores had more active and/or positive involvement with a family member than young people with lower resilience scores. Many young people also had relationships with extended family (siblings, aunts, uncles, grandparents). The resilience measure specifically captured information on a range of caregiving relationships and included both psychological and physical caregiving dimensions, so youth who had a wider range of family available to act in these roles scored higher on the resilience measure. Family, both nuclear and extended, were often a first port of call for young people despite sometimes troubled relationships and histories. It is notable that in both the higher and lower resilience groups birth fathers were often absent from young people’s lives.

Change did, however, affect service delivery. The following file excerpt demonstrates how a single, short-term change had a number of flow-on effects:

Guy had three placements in 12 months. He had not attended school as his behaviours 
were deemed by the school to place other students at risk. He had been with a tracker daily and this started to become difficult. Guy had one appointment with the mental health service, in [town A]. When he was placed in [town B] with maternal family members, he was assessed by a psychiatrist who diagnosed him as having a severe conduct disorder and prescribed him medication. Guy then moved back to [town A] where the mental health service required a new full assessment. He appeared to be in a state of limbo.

Not only were Guy's physical circumstances and relationships disrupted, but therapeutic interventions were also delayed, limiting his ability to progress in other areas.

Despite intensive and multiple agency involvement, this file summary points to the difficulties in providing adequate services when a young person's life lacks stability (James, Fraser, \& Saville-Smith, 2011). Services may be unwilling to begin or persist with work if placements are short term and time can pass quickly with what appears to be little improvement for a young person. Young people may find it difficult to engage with and commit to placements, schools, services, and relationships if their experience has been that carers, workers, or programmes do not "last the distance". In such situations services may be unconsciously mirroring young people’s experiences (Ruch, Turney, \& Ward, 2010). Conversely, without intervention it may be difficult to create stability for a young person who demonstrates challenging behaviours or who lives in a family that is experiencing difficulties.

\section{Relationship Resources for Managing Change}

\section{The role of family}

Evidence from the case file summaries and the interviews with young people suggested many perceived family as a key support during periods of change and valued the ongoing nature of these relationships, sometimes regardless of their quality and even when they had experienced harm within family settings. Families appeared to play different roles in supporting young people through change: as caregivers and/or providers of material support, as providers of emotional support, and in their least active forms as an "emotional copresence" (Holland \& Crowley, 2013, p. 261). The notion of belonging was central to these relationships. In this regard, they comprise a critical dimension that service providers must take account of in their work with young people.

Young people in the higher resilience group tended to have more positive and active relationships with at least one adult member of their extended family although not necessarily their parents. In most cases family cared for young people full time, providing them with material and emotional support. Situations were not always ideal however. Some file summaries showed evidence of family violence or parental substance abuse within home settings and in other instances, young people were dealing with their own issues of sexual abuse, addiction, mental health, or learning disabilities.

There were two sub-groups within the lower resilience group; those with ambivalent relationships with family and those for whom family was largely unavailable. In the first subgroup, young people were cared for by their family who provided them with material support and maintained involvement in their lives; despite ambivalent or poor relationships, young people recognised the support their family provided. For these young people, living with family who provided a continuous or familiar living environment despite certain challenges 
was preferable to living independently or in out-of-home care; young people felt comforted by familiar behaviours, norms, and expectations (Holland \& Crowley, 2013; Snow et al., 2013).

In the second sub-group, family was largely unavailable for reasons including parental death, imprisonment, mental health issues, addictions, family violence, patterns of harmful behaviour across the extended family, or where family had rejected youth. Some of these young people did not perceive their family settings as harmful despite evidence to the contrary. They held idealised views of their families and longed to be with them, experiencing them as a comforting emotional support or co-presence (Biehal \& Wade, 1996; Holland \& Crowley, 2013). Young people absconding from placements to return home was a common occurrence among these youth as demonstrated in the following file summary:

Social worker visited Angela and found that she had been residing with her mother [who has serious mental health problems] and maternal grandmother for past 6 weeks, and had not informed the social worker of this. File noted that Angela stated she would "vote with her feet" if she was placed back with caregivers, as she wished to remain with her mother.

In a number of instances families acted as emergency placements when other placements broke down. This occurred even when those same families had previously requested young people be placed elsewhere, or when social workers had, in the past, deemed family placements inappropriate. In the case of the latter, additional supports or safety plans were usually put in place.

The need to belong was a key theme amongst young people who had the least involvement with their families as demonstrated by this file summary:

Ngaio was described as really distressed, didn't want to go in residence, felt very lonely, had no-one to belong to.... She was then placed with another new caregiver. Her worker stated she was very much wanting a long term placement, was "sick of feeling that no-one wants her".

For this group of young people, family was a representation, a longed for dream:

Maree said that throughout her childhood she would often, and sometimes still does, look at others and wish she had a "normal childhood", "a happy childhood"; she is not sure what a normal childhood looks like but she would describe it as "a life that's not mine” [excerpt is a summary from an interview where a recording device could not be used].

Despite the harm they had experienced in their care, these young people commonly identified parents as important people in their lives. The complexity of these relationships can be difficult to grasp but the role of parents or families of origin in such cases may be as an identity resource (Chen et al., 2012; Snow et al., 2013), offering young people "interwoven" biographies (Holland \& Crowley, 2013, p. 64) which contribute to their sense of self (Ruch et al., 2010) and potentially to their sense of security (Cashmore \& Paxman, 2006). This may also explain the important role that relationships with siblings play for these young people. As one young person stated in an interview: 
It's hard because I miss my family and you don't get to see your family much...not the little kids, the ones that I love so much.

These notions are the basis for arguments that support continued contact between young people and their families once they have been placed in care. However, evidence regarding the effects of contact on long-term placement stability is mixed (Rock et al., 2013) suggesting care must be taken in how young people's expectations of such contact are managed.

Families appeared to provide increasing levels of material support as young people transitioned into adulthood, a period of significant change. Despite many young people having at some stage been in care, at the time of the research over half lived with their parents or other family (the remainder lived independently, in residential care, or were homeless). Some file summaries raised questions about the extent of support offered to families to help them overcome original issues of concern particularly where a young person's return home was unplanned.

Interestingly, a number of the young people in the higher resilience group had experiences similar to young people in the lower resilience group including repeated safety concerns, parents suffering from mental health issues or addictions, and multiple changes to living arrangements. The key difference appeared to be the contextual support available to young people in the higher resilience group, and in many cases the active work by services to provide the young people with a safe environment or to support families to support their young people.

\section{Relationships with services}

Young people in both the higher and lower resilience groups described being supported through periods of change by a range of services. One emerging theme was that of worker persistence and commitment. The following file summary illustrates the way in which a school provided extensive support for Ruby, giving her stability during a period of change:

Social worker had spoken with Ruby's teacher who said Ruby [was] missing her father.... The teacher reported there was a plan for Ruby to have dinner at her grandmother's home; her caregiver also supported this. Ruby was due to start counselling. She had reported nightmares/sleeping problems as well as other symptoms. School had found a clinical psychologist who was willing to work with her. School was working on specific future orientated tasks with Ruby on an informal level. Ruby was able to access the school counsellor and Deputy Principal for support. School was going to investigate medication with her doctor.

Persistence and commitment may also enhance a service's engagement with young people, as demonstrated in Anton's file where the social worker made weekly home visits over a sixmonth period (prior to Anton turning 17). While it is not possible to attribute causality, it is notable that Anton reported favourably on their relationship and the worker's ability to listen. After the research interview, Anton elaborated on this, as captured in the following field note:

Anton finds current social worker very helpful. After [the research interview] tape was stopped he elaborated and said she was really good - in terms of a service that has stood out. She listens, doesn't make judgements, hears what he says. He said that 
the social worker "has the ability to listen without thinking she knows best, she knows how to listen”.

These findings are consistent with Ruch's et al. (2010) research into relationship-based practice which suggests worker persistence aids in developing effective relationships, modelling to clients a "reliable, engaged and constructive relationship" (Ruch et al., 2010, p. 15) and enhances their ability to regulate their own lives. In attachment terms such a relationship contributes to a "secure base" from which, over time, the client will be able to develop their own internal working model and provide stability for themselves (Ruch et al., 2010; Schofield \& Beek, 2009).

Knowing a service is available to them on an ongoing basis was reassuring for some young people, as demonstrated in the following interview quote:

I can just ring [service], they said I can come back any time so if I do get in the shit I can just ring them up the next couple of days after my call they will come pick me up...I am gonna go back. Even after when I'm off their books I'm gonna go back. 'Coz they're like [family] to me, I look up to them, they're like family.

His connection to the service enabled this young man to plan for the future; he was motivated to stay out of trouble by the prospect of living independently from his family and with the support of the service. In cases where young people do not have an active family relationship or where family connections are poor, long-term relationships with services may be even more important, acting as "guardians of narrative threads in the lives of children" (Hurley, Martin, \& Hallberg, 2013, p. 267).

It is notable that of the 16 files reviewed, young people with higher resilience scores generally experienced longer term involvement with services than those with lower resilience scores (although this involvement was not usually continuous) and were more likely to have recent or current involvement with a service. Over half of this group also described having a good relationship with at least one service. While this may suggest that positive, ongoing involvement with services plays a role in building young people's resources, it may also reflect that young people who have more resources to begin with have greater capacity to negotiate involvement with services (Sanders et al., 2013b; Ungar, 2005). The examination of the role of long-term service involvement in good outcomes for youth with complex needs is an important area for further investigation.

\section{Families and services: combined resources}

While most young people had some level of connection with their family of origin, the file analysis revealed that those with higher resilience scores were more likely to have enduring relationships (long term, active, and relatively positive) with both family and a service provider. In contrast, young people with lower resilience scores were more likely to have only one form of support or to lack enduring adult support altogether. This is consistent with previous findings (Sanders et al., 2013a; Cashmore \& Paxman, 2006).

The following interview excerpt illustrates the positive effects of complementary support from both family and a service in helping one young person cope with her long-term residential placement. While in care, Sonia's basic needs (food, shelter, safety) were met, which in the past she and her family had struggled to provide. Members of her family visited 
regularly and it was clear the statutory service also supported them, empowering them to support their daughter. Sonia stated:

it's safe for me and I feel like the staff are supporting me. While I'm here, caring for me... they help me,...tenderly care for me...Helping my family out...

In this case, the service took account of and built on Sonia's existing resilience resources, particularly those of her family. This cooperative approach to supporting Sonia may have contributed to her positive engagement with both her family and the service, building up her network of enduring relationship resources for the future.

In contrast, where services and family are unable to work together effectively, a young person's resources and ability to manage change, such as moving toward independent living, may be reduced. The following file summary captures this:

A pattern was noted where his mother wanted him to be cared for by someone else, and then when he was moved away from her she wanted him back. When he returned she would refuse to work with agencies to ensure that the return was successful and that his needs were met.

In this case the service was considering closing the file because they were unable to engage with the family; a relationship-based approach (Ruch et al., 2010) would encourage services to further explore how to positively engage with the young person's mother.

Services may supplement the roles of family relationships (as providers of care, emotional support, or emotional co-presence) as required but particularly when families are unavailable as a resource. Services may provide a secure base to young people and in doing so contribute to their sense of security (Cashmore \& Paxman, 2006). While noting that there may be risks of fragmentation where multiple agencies are involved with a young person, there are implications for ensuring young people with complex needs continue to have a relationship with at least one service as well as with their family where possible, as they move toward independence. The ways in which different factors influence young people's future orientations as they move into independence will be explored in detail in the Youth Transitions study which follows the group of multiple service using youth for up to six years (see www.youthsay.co.nz).

\section{Discussion And Implications For Social Work Practice}

A key finding of this study is the importance of enduring relationships, particularly those with family and services, as resources in supporting young people through periods of change. At first glance the implications appear straightforward: that family, services and other adults involved with young people with complex needs should strive to support young people through change by providing and nurturing enduring relationships. Solutions are more nuanced than this however, particularly with regard to young people and their families. Some families may require support in order to offer their young people enduring relationships and workers can provide this in a number of ways: through relationship counselling, interventions to address underlying problems that affect family relationships (for example, treatment for parental alcohol abuse, or addressing issues of family violence), or, as in Sonia's case, providing guidance and physical resources to families (for example, transportation) to enable them to have meaningful contact with their young person. 
In other cases, workers may feel cautious about young people idealising the memories of family who have in the past caused them harm, been unavailable to care for them, or rejected them. These young people may have the most to gain from enduring relationships with services, including stable placements with long-term caregivers. Placement stability is likely to create stability in other aspects of young people's lives, contributing to their sense of security (Cashmore \& Paxman, 2006). Cashmore and Paxman (2006, p. 239) suggest "timely decisions" are needed when young people enter care, rather than prolonged instability. In New Zealand, Home for Life policy developments (Child, Youth and Family, 2012) provide guidance about timely decision-making regarding placement permanency and address the need for continuity of the caregiving relationship.

Schofield and Beek (2009) advocate for a model of long-term foster care that offers young people with complex needs, who are unable to return home, a sense of security throughout their lives. Many young people in care will, however, go on to have contact with their families (Cashmore \& Paxman, 2006; Schofield \& Beek, 2009; Stein \& Munro, 2008) and services that work towards enhancing these relationships or that equip young people with the skills and resources to negotiate safe, healthy, and enduring future relationships including complex family relationships (Fernandez, 2006) will contribute positively to young people's outcomes.

In terms of relationships between young people and services (including caregivers and mentors), the findings encourage longevity even in the face of challenge. Relationship-based social work (Ruch et al., 2010) holds promise for services in engaging challenging clients and building enduring relationships. Grounded in psychodynamic, systemic, and attachment theories, this approach values the relationship between services and clients as a therapeutic intervention in itself. It requires workers to work "in and with" often stressed relationships (Ruch et al., 2010, p. 9). Both this and long-term foster care approaches can be emotionally demanding, time consuming, and resource intensive, requiring workers and carers to be well supported and supervised.

However, there are other challenges to sustaining service-client relationships at an organisational level. Contemporary organisational pressures, "performative" trends (Cooper, 2010, p. 229) and “increased prescription and bureaucratic processes” (Munro, 2011, p. 87) have moved social workers away from relationship-based approaches to focus instead on completing prescribed tasks, despite experts suggesting that there should be a greater focus on assisting social workers to work effectively with their clients (Munro, 2011). Examples of performative trends were evident in the analysis of case file data. Notes on several files stated that the service's involvement would be withdrawn because the young person had not attended clinic appointments, their family was unwilling to engage with the service, or because the service believed it wasn't making a sufficient difference to the young person's life. In several instances the existence of other support networks for the young person (for example, family or other agencies) was given as a reason for services withdrawing. In other cases, services withdrew when agreed plans were completed despite young people continuing to demonstrate support needs. In none of these cases were problems "solved”.

Some files, like Guy's, demonstrated the challenges of multiple system involvement with young people with complex needs, revealing the pitfalls of inadequate planning and disjointed service delivery. Integrated service delivery - which utilises a lead agency, follows a carefully designed plan that takes into account a young person's full range of needs and 
existing resources (including the needs of parents or carers), and identifies appropriate services to work with those resources - may provide a starting point in such cases.

As the findings here suggest, services (child welfare, juvenile justice, mental health, and education in both statutory and non-government agencies) need to be prepared for longterm involvement with young people with complex needs and to "stay with" these relationships even during periods of change and tension until desired outcomes are achieved. The potential for such arrangements to occur in New Zealand may be enhanced by recent announcements under the Children's Action Plan (New Zealand Government, 2012) for shared accountability for vulnerable children across multiple government agencies (social development, health, education, police, and justice).

\section{Conclusions}

Change is correlated with poor outcomes for young people with complex needs and can undermine a young person's support networks (James et al., 2011; Stein \& Munro, 2008). This analysis provides evidence that relationships that endure, particularly those with family and some services, provide support in a range of forms for young people and assist youth through difficult processes of change. Young people with complex needs are most well equipped to navigate change when they are supported by enduring relationships with both family and a service, at least until the young person is able to develop an internal working model of stability (Ruch et al., 2010; Schofield \& Beek, 2009).

Equipping young people in this way is a complex process. Families may only have the capacity to provide young people with an emotional co-presence in the form of memories and imaginations during times of change. The challenge for services working with young people is to help them to develop adaptive strategies to manage sometimes conflicting emotions and family relationships. Relationship-based practice encourages workers, supported by their organisations, to "stay with" clients during these difficult times and in doing so build the enduring relationships young people require. There are practical challenges to such an approach however, such as age-related service thresholds. It may be timely to explore opportunities to work beyond such thresholds, to provide the most empowering services and support for young people during critical periods of their development. Even when relationships are not ideal, they may be able to contribute to the range of resources young people have to draw on. As Gilligan (2006) notes:

Given how difficult it is to engineer positive futures for vulnerable children that prove effective and sustainable, our approach should be to draw on as wide a repertoire of resources as possible. We should be striving to paint the future from a broad palette of existing and new possibilities. Our goal should be to maximise the range of social and emotional assets the young person can call upon. (p. 33)

Taken together, the findings from the study reported here, provide an argument for promoting the availability of relationship-based, long-term service involvement with young people with complex needs, highly committed service involvement where the young person has little or no contact with family, and the continued involvement of services even when family is available to the young person. The roles of committed caregivers and mentors are central to the circle of support that young people require to help them achieve positive outcomes and, where family are unable to play these roles, it is in all of our interests that other, skilled adults are well supported to do so. 


\section{References}

Ainsworth, M. D. S., \& Bell, S. M. (1970). Attachment, exploration, and separation: Illustrated by the behavior of one-year-olds in a strange situation. Child Development, 41, 49-67. http://dx.doi.org/10.1111/j.1467-8624.1970.tb00975.x

Atwool, N. (2010). Children in Care. A report into the quality of services provided to children in care. Wellington, New Zealand: Office of the Children's Commissioner.

Biehal, N., \& Wade, J. (1996). Looking back, looking forward: Care leavers, families and change. Children and Youth Services Review, 18 (4/5), 425-445.

http://dx.doi.org/10.1016/0190-7409(96)00013-8

Barber, J. G., \& Delfabbro, P. H. (2006). Psychosocial well-being and placement stability in foster care: Implications for policy and practice. In R. Flynn, P. Dudding, \& J. Barber (Eds.), Promoting resilience in child welfare (pp. 157-172). Ottawa, Canada: University of Ottawa Press.

Cashmore, J., \& Paxman, M. (2006). Predicting after-care outcomes: The importance of 'felt' security. Child and Family Social Work 2006: 11, 232-241 http://dx.doi.org/10.1111/j.1365-2206.2006.00430.x

Chen, J., Lau, C., Tapanya, S., \& Cameron, C. A. (2012). Identities as protective processes: Socio-ecological perspectives on youth resilience. Journal of Youth Studies, 15(6), 761-779. http://dx.doi.org/10.1080/13676261.2012.677815

Child, Youth and Family. (2012). Permanent care and creating a home for life policy. Retrieved from http://www.practicecentre.cyf.govt.nz/policy/permanent-care-andcreating-a-home-for-life/

Cooper, A. (2010). What future? Organisational forms, relationship-based social work practice and the changing world order. In G. Ruch, D. Turney, \& A. Ward (Eds.), Relationship-based social work: Getting to the heart of practice (pp. 148-163). London: Jessica-Kingsley Publishers.

Driscoll, J. (2011). Making up lost ground: Challenges in supporting the educational attainment of looked after children beyond key stage 4. Adoption \& Fostering, 35, 18-31. DOI: 10.1177/030857591103500203

Erikson, E. H. (1965). Childhood and society. Harmondsworth, UK: Penguin in association with Hogwarth press.

Fernandez, E. (2006). Growing up in care: Resilience and care outcomes. In R. Flynn, P. Dudding, \& J. Barber (Eds.), Promoting resilience in child welfare (pp. 131-156). Ottawa, Canada: University of Ottawa Press.

Gilligan, R. (2006). Creating a warm place where children can blossom. Social Policy Journal of New Zealand Journal, 28, 36-45.

Holland, S., \& Crowley, A. (2013). Looked-after children and their birth families: Using sociology to explore changing relationships, hidden histories and nomadic childhoods. Child and Family Social Work, 18, 57-66. http://dx.doi.org/10.1111/cfs.12032 
International Journal of Child, Youth and Family Studies (2014) 5(3): 447-465

Hurley, D.J., Martin, L., \& Hallberg, R. (2013). Resilience in child welfare: A social work perspective. International Journal of Child, Youth and Family Studies, 4(2), 259-273.

Jakobsen, T. B. (2012). Anti-social youth? Disruptions in care and the role of 'behavioural problems'. Children and Youth Services Review, 35(9), 1455-1462 http://dx.doi.org/10.1016/j.childyouth.2013.05.012

James, B., Fraser, R., \& Saville-Smith, K. (2011). The movement of children and young people who are CYF clients in the four case study communities. Retrieved from http://www.cresa.co.nz/wp-content/uploads/2011/06/cyf-paper-final-_james_.pdf

Munro, E. (2011). The Munro review of child protection: Final report: A child-centred system. London: United Kingdom Department of Education.

New Zealand Government. (2012). Children's action plan: Identifying, supporting and protecting vulnerable children. Wellington, New Zealand: Author.

Plumridge, E., \& James, B. (2011). Shifting, circulating and staying: Understanding young people's movement. Retrieved from http://www.cresa.co.nz/wpcontent/uploads/2011/06/young-people-movement-and-attachment-final.pdf

Rock, S., Michelson, D., Thomson, S., \& Day, C. (2013). Understanding foster placement instability for looked after children: A systematic review and narrative synthesis of quantitative and qualitative evidence. British Journal of Social Work, 43(4), 1-27. DOI: $10.1093 /$ bjsw/bct084

Ruch, G., Turney, D., \& Ward, A. (2010). Relationship-based social work: Getting to the heart of practice. London: Jessica-Kingsley Publishers.

Sanders, J., Munford, R., Liebenberg, L., Ungar, M., Thimarsarn-Anwar, T., Johnston, W., et al. (2013a). The human face of vulnerability: The Pathways to Resilience Study (Technical report 3). Retrieved from http://www.youthsay.co.nz/massey/fms/Resilience/Documents/The\%20Human\%20Fa ce\%20of\%20Vulnerability.pdf

Sanders, J., Munford, R., Liebenberg, L., Ungar, M., Thimarsarn-Anwar, W., Youthline New Zealand, et al. (2013b). The impact of consistent service quality on outcomes and opportunities for vulnerable youth: The Pathways to Resilience Study (Technical report 5). Retrieved from

http://www.youthsay.co.nz/massey/fms/Resilience/Documents/Consistent\%20Service \%20Quality.pdf

Sanders, J., Munford, R., Thimasarn-Anwar, T., Liebenberg, L., Ungar, M., Osborne, A.,et al. (2013c). Methodological overview: The Pathways to Resilience Study (Technical report). Retrieved from

http://www.youthsay.co.nz/massey/fms/Resilience/Documents/Methodological\%200 verview.pdf

Schofield, G., \& Beek, M. (2009). Growing up in foster care: providing a secure base through adolescence. Child and Family Social Work, 14(3), 255-266. http://dx.doi.org/10.1111/j.1365-2206.2008.00592.x 
Smith, J., Kumar, R., Nicholson, K., \& Kumar, J. (2006). Stigma, rights, resilience and stability. Social Policy Journal of New Zealand, 27, 12-19.

Snow, K., \& The Voyager Project, Toronto. (2013). Aspirations and belonging: Touchstones for the journey. International Journal of Child, Youth and Family Studies, 4(3), 381390.

Solomon, R. (2010). Working with endings in relationship-based practice. In G. Ruch, D. Turney, \& A. Ward (Eds.), Relationship-based social work: Getting to the heart of practice (pp. 164-182). London: Jessica-Kingsley Publishers.

Stein, M. (2006). Resilience and young people leaving care: Implications for child welfare policy and practice in the UK. In R. Flynn, P. Dudding, \& J. Barber (Eds.), Promoting resilience in child welfare (pp. 264-278). Ottawa, Canada: University of Ottawa Press.

Stein, M., \& Munro, E. (2008). Young people's transitions from care to adulthood: International research and practice. London: Jessica Kingsley Publishers.

Tarren-Sweeney, M. (2008). Retrospective and concurrent predictors of the mental health of children in care. Children and Youth Services Review, 30(1), 1-25. http://dx.doi.org/10.1016/j.childyouth.2007.05.014

Ungar, M. (2001). The social construction of resilience among "problem” youth in out-ofhome placement: A study of health-enhancing deviance. Child and Youth Care Forum, 30(3), 137-154.

Ungar, M. (2004). The importance of parents and other caregivers to the resilience of highrisk adolescents. Family Process, 43(1), 23-41. http://dx.doi.org/10.1111/j.1545-5300.2004.04301004.x

Ungar, M. (2005). Pathways to resilience among children in child welfare, corrections, mental health and educational settings: Navigation and negotiation. Child \& Youth Care Forum, 34(6), 423-444. http://dx.doi.org/10.1007/s10566-005-7755-7

Ward, H. (2011). Continuities and discontinuities: Issues concerning the establishment of a persistent sense of self amongst care leavers. Children and Youth Services Review, 33(12), 2512-2518. http://dx.doi.org/10.1016/j.childyouth.2011.08.028 